\title{
RELATION BETWEEN THE MODEL AND THE TOPOGRAPHY OF THE OBJECTIVE FUNCTION IN A VELOCITY ANALYSIS USING A NONHYPERBOLIC MULTICOMPONENT TRAVEL-TIME APPROXIMATION
}

\author{
Nelson Ricardo Coelho Flores Zuniga ${ }^{1}$, Fernando Brenha Ribeiro ${ }^{1}$ \\ and Viatcheslav Ivanovich Priimenko²
}

\begin{abstract}
The velocity analysis is an important step for the seismic processing. With the increase in the difficulty of work with specific conditions and complex geological structures, more complex travel-time approximations are developed to perform a better structural characterization. As the complexity increases, more approximations were developed aiming to characterize different factor responsible for the nonhyperbolicity, and using sometimes an additional parameter. Many nonhyperbolic multiparametric travel-time approximations were developed and their complexities vary strongly from one to other. In previous works, it was observed that some approximations present a unimodal behavior while other approximations showed a multimodal behavior. However, a specific kind of approximation showed both statistical distributions, the unimodal and the multimodal in distinct situations. To find out the factor responsible for this variation in the probabilistic distribution behavior of this kind of approximation, it was necessary to test different theoretical models to understand which variation in the structure interferes in the topography of the objective function.
\end{abstract}

Keywords: objective function, nonhyperbolic, probability distribution.

RESUMO. A análise de velocidades é uma etapa importante para o processamento sísmico. Com o aumento da dificuldade em se trabalhar com condições específicas e estruturas geológicas complexas, são desenvolvidas aproximações de tempos de trânsito mais complexas para realizar uma melhor caracterização estrutural. Conforme a complexidade aumenta, mais aproximações são desenvolvidas com 0 objetivo de caracterizar diferentes fatores responsáveis pela não-hiperbolicidade, e usando parâmetros adicionais em alguns casos. Muitas aproximações não-hiperbólicas multiparamétricas de tempos de trânsito foram desenvolvidas e suas complexidades variam fortemente de uma para a outra. Em trabalhos anteriores foi observado que algumas aproximações apresentaram um comportamento unimodal, enquanto outras aproximações mostraram um comportamento multimodal. Entretanto, um tipo específico de aproximação mostrou ambas as distribuições estatísticas, a unimodal e a multimodal, em diferentes situações. Para encontrar o fator responsável por esta variação no comportamento da distribuição probabilística desse tipo de aproximação, foi necessário testar diferentes modelos teóricos para entender qual variação na estrutura interfere na topografia da função objetivo.

Palavras-chave: função objetivo, não-hiperbólica, distribuição probabilística.

\footnotetext{
${ }^{1}$ Universidade de São Paulo, Instituto de Astronomia, Geofísica e Ciências Atmosféricas (IAG-USP), Departamento de Geofísica. Rua do Matão 1226 - Cidade Universitária, São Paulo, SP, Brazil - E-mails: nelson.zuniga@iag.usp.br, fernando.brenha@iag.usp.br

${ }^{2}$ Universidade Estadual do Norte Fluminense (UENF), Laboratório de Engenharia e Exploração de Petróleo (LENEP), Avenida Brennand s/n - Imboacica, Macaé, RJ, Brazil-E-mail: slava@lenep.uenf.br
} 


\section{INTRODUCTION}

As the geological structures were been found, more complex techniques, methods, algorithms and equations were developed to perform a better characterization, and in the seismic survey it was not different. The velocity analysis is an important step to reach a good characterization concerning the stratigraphy.

Many travel-time approximations were developed to describe different behaviors of the nonhyperbolicity once the hyperbolic approach, proposed by Dix (1955), was not valid in some cases. Malovichko (1978) proposed the shifted hyperbola approach, a nonhyperbolic approximation focusing the heterogeneity parameter $\mathrm{S}$, to characterize the nonhyperbolicity due to the heterogeneity associated to large offsets. Other approximations were lately developed using the same heterogeneity parameter (Ursin \& Stovas, 2006; Blias, 2009).

The nonhyperbolic multiparametric travel-time approximations vary significantly concerning their complexities. Even with other authors working with comparison of travel-time approximations (Aleixo \& Schleicher, 2010; Golikov \& Stovas, 2012), none of them presented a complexity analysis concerning the objective function of the approximations. However, more recent works showed this kind of analysis for PP and PS events (Zuniga, 2017; Zuniga et al., 2015, 2016a,b, 2017). For this reason, it was possible to observe that there are approximations which presented always a unimodal (there is only the global minimum region) behavior in the topography of the objective function (Malovichko, 1978; Alkhalifah \& Tsvankin, 1995). And on the other hand, there are also approximations which always behaved as a multimodal (there is both global and local minimum regions) distribution (Muir \& Dellinger, 1985; Li \& Yuan, 2001). However, in some cases it was observed that the Ursin \& Stovas (2006) and the Blias (2009) approximations have a variation in the statistical distribution as they showed sometimes a unimodal behavior, and other times a multicomponent behavior.

To understand what causes this variation in the statistical distribution, many numerical models were tested, for the Blias (2009) approximation, varying the water depth and the depth of the lowest reflection interface, representing the top of the reservoir.

With the residual function maps (Larsen, 1999; Kurt, 2007) of each model tested here, it is possible to reach information about how the structure of the model interferes in the topography of the objective function for this nonhyperbolic multiparametric travel-time approximation.

\section{METHOD}

To perform the tests, it was necessary to select several models with different and controlled characteristics to understand which factor interferes in the structure of the topography concerning the objective function.

The models had to be very similar to each other varying only some characteristics to isolate the reason of the variation in the statistical distribution. Thus, nine theoretical models were selected and modeled with variations about the water depth and the thickness of the structure above the top of the reservoir (Table 1). The data were modeled as an OBN (Ocean Bottom Nodes) acquisition to obtain both conventional PP and converted PS reflection events.

The Eq. (1), Blias (2009) travel-time approximation, uses not only the offset as vector, and time for zero offset $\left(t_{0}\right)$ and RMS (Root Mean Square) velocity $(v)$ as variables, but also the $S$ parameter, the heterogeneity parameter.

$$
t=\frac{1}{2}\left[t_{0}^{2}+\frac{1-\sqrt{S-1}}{v^{2}} x^{2}\right]^{1 / 2}+\frac{1}{2}\left[t_{0}^{2}+\frac{1+\sqrt{S-1}}{v^{2}} x^{2}\right]^{1 / 2}
$$

To perform the complexity analysis of the objective function, the residual function maps (Larsen, 1999; Kurt, 2007) were used.

At first, the inversion routine of the velocity analysis was performed to each model with the Blias (2009) approximation. And the residual function maps were generated pointing both global and local minimum regions.

As the $t_{0}$ is the less sensible variable, it was fixed as constant after the inversion. The RMS velocity and the additional parameter (heterogeneity parameter) are described over the axes, respectively over the ordinate and over the abscissa. The minimum value is described over the third dimension in the hyperplane.

With this set of information is possible to identify in which model the Blias (2009) approximation stops to behave as a multimodal and starts to behave as a unimodal distribution.

\section{RESULTS}

It is possible to observe, in the Figure $1 \mathrm{~A}$, that the Blias (2009) approximation presents a strong multimodal behavior with several local minimum regions next to each other. For the Model 1 , it can also be seen that the topographic structure is extremely complex. In the Figure 1B, representing the Model 2, it is possible to observe a little softer topography and only one local minimum region. It is shown, in Figure $1 \mathrm{C}$, only one local minimum region, 
and also a little decrease in the complexity of the topography structure of the Model 3.

In the Model 4 (Fig. 2A), it is possible to observe a softer structure, with a clearly smaller local minimum region. In the Figure 2B (Model 5), the local minimum region is much smaller and it is observed a more homogenous topography. A much more homogeneous topography structure can be seen in the Model 6 , with a very small local minimum region (Fig. $2 \mathrm{C}$ ).

In the Figure $3 \mathrm{~A}$, it is possible to observe a residual local minimum region in a much more homogeneous topography concerning the Model 7. In the Figure 3B, it is not possible to observe the local minimum region anymore. Different than the other models, Model 8 showed an extremely homogeneous structure which not only attenuated the local minimum region, but suppressed the local minimum region completely. Similar to Model 8, it is possible to observe in Figure 3C (Model 9), an extremely homogeneous topographic structure with no local minimum region. And it is also even more homogeneous than the other models.

In the Figure 4A, it is showed by the Model 1 with a PS wave reflection event a very complex topographic structure with a multimodal behavior similar to the conventional reflection event. The converted wave event for the Model 2 (Fig. 4B) presents a softer topography and still behaving as a multimodal statistical distribution. It is observed, in Figure 4C (Model 3), a similar behavior than the two previous Models, with a complex structure and a multimodal behavior.
In the Model 4, represented by the Figure 5A, it was observed a softer structure and a narrower local minimum region. It is shown by the Model 5, in Figure 5B, a little smaller local minimum region and a little more homogeneous topography. Only in the Model 6 (Fig. 5C), it is possible to observe a much narrower local minimum region and a significantly more homogeneous topographic structure of the objective function.

As it was observed in the Model 7 with the conventional reflection event, the Figure $6 \mathrm{~A}$ showed a residual local minimum region for the PS reflection event. In the Figure $6 \mathrm{~B}$, there is no local minimum region. Thus, the approximation showed a unimodal behavior for the converted wave reflection event of the Model 8. Similar to the Figure 3B, the local minimum region is completely suppressed and presents a homogeneous objective function structure. The PS wave reflection event of the Model 9 (Fig. 6C) showed an extremely homogeneous topographic structure of the objective function with no local minimum region.

Concerning the global minimum region, it becomes larger as the local minimum region disappears. It can also be observed that the difference between the maximum regions and the global minimum region became smaller as the structure becomes softer.

It was also observed that with the increase of the depth of the interface where occurs the reflection, there is a decrease of the complexity of the topography. There is an attenuation and after a suppression of the local minimum region, and also a homogenization of the structure. For the PS event, the attenuation of the local minimum region starts occur strongly in the Model 5

Table 1 - Models and their variations about the water depth, structure thickness and the top of the reservoir depth.

\begin{tabular}{|c|c|c|c|}
\hline Model & Water depth $(\mathrm{m})$ & Structure thickness $(\mathrm{m})$ & Top of the reservoir depth $(\mathrm{m})$ \\
\hline 1 & 0 & 1000 & 1000 \\
\hline 2 & 1000 & 1000 & 2000 \\
\hline 3 & 2000 & 1000 & 3000 \\
\hline 4 & 0 & 2000 & 2000 \\
\hline 5 & 1000 & 2000 & 3000 \\
\hline 6 & 2000 & 2000 & 4000 \\
\hline 7 & 0 & 3000 & 3000 \\
\hline 8 & 1000 & 3000 & 4000 \\
\hline 9 & 2000 & 3000 & 5000 \\
\hline
\end{tabular}


A

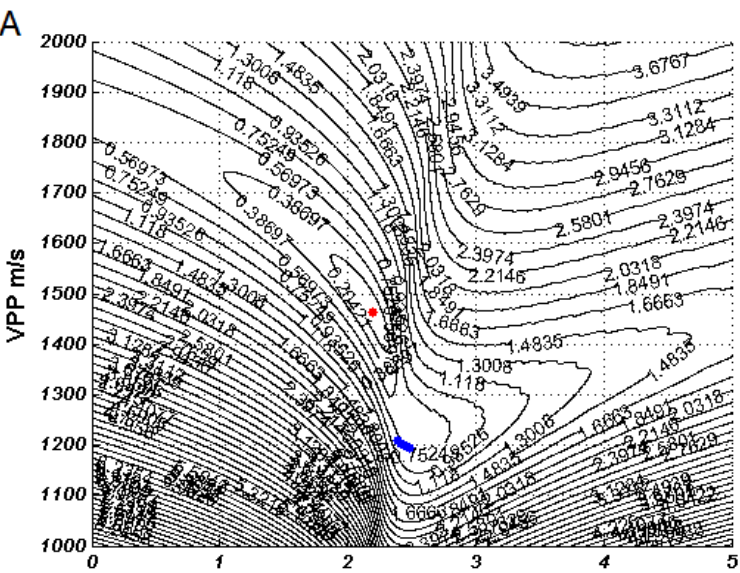

B

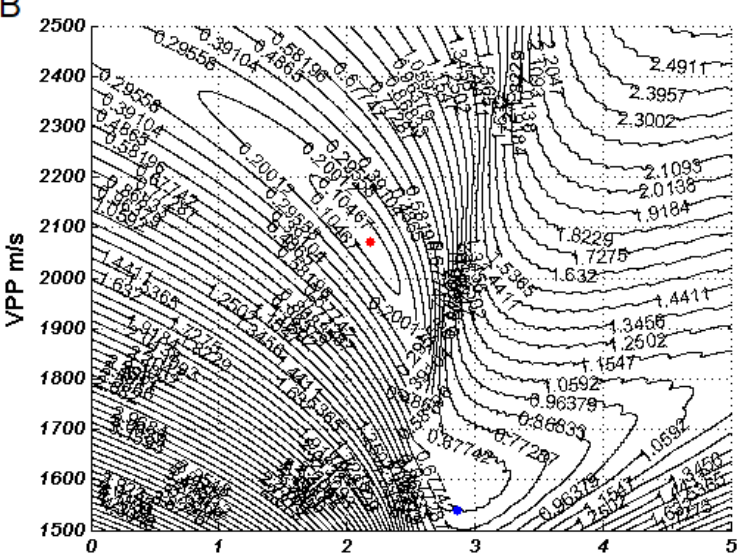

C

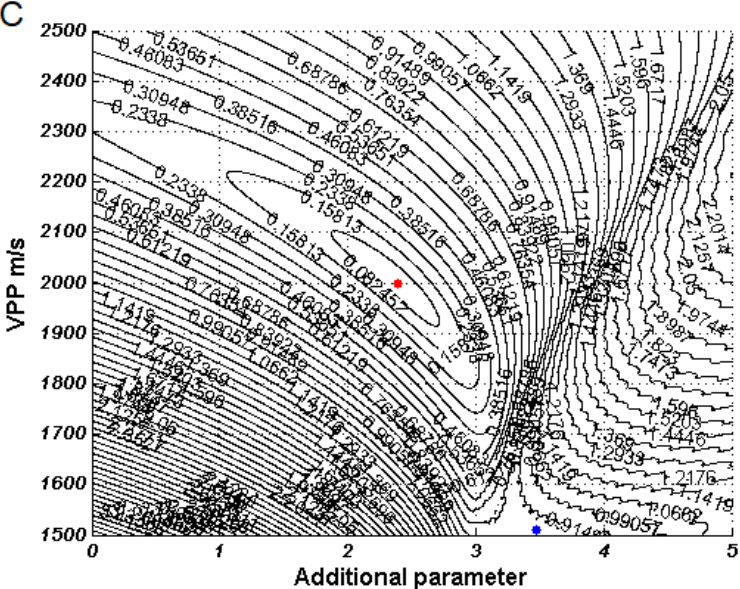

D $\quad V_{p}(\mathrm{~m} / \mathrm{s})$

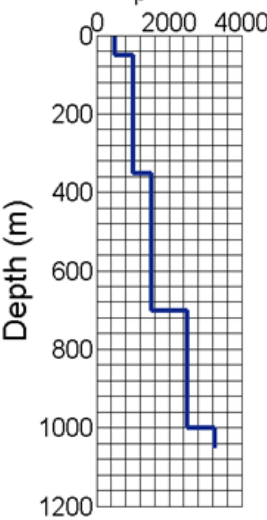

E
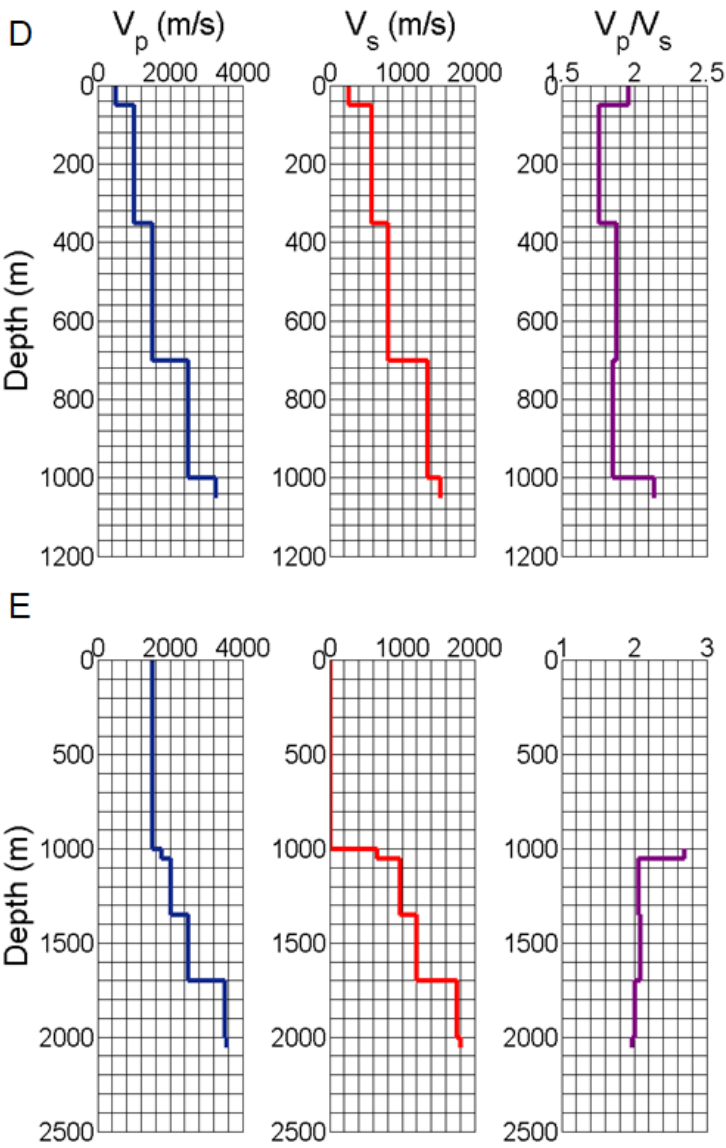

$\mathrm{F}$

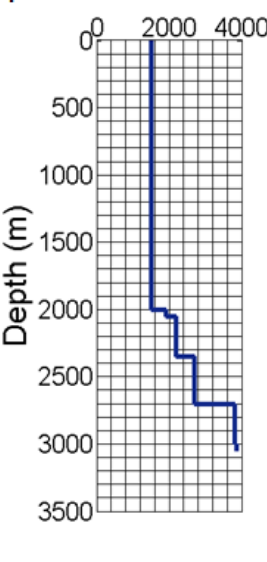

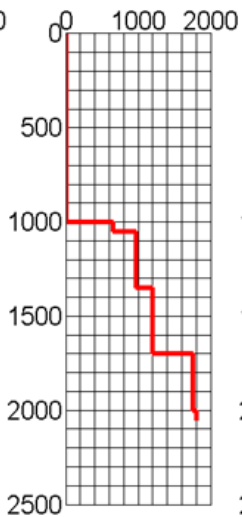
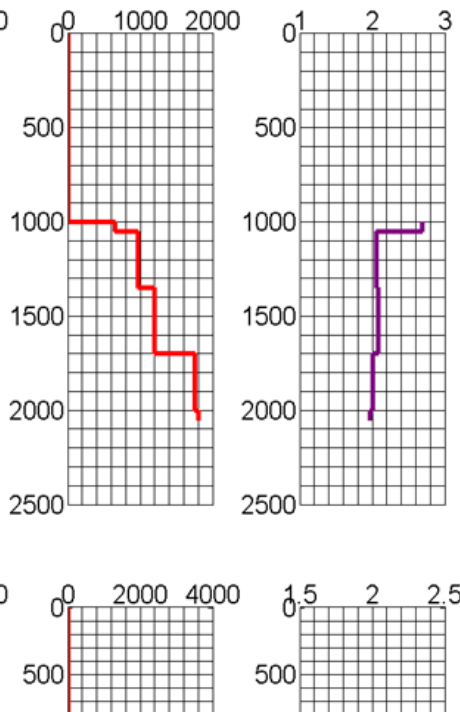

$\begin{array}{lll}1.5 & 2 & 2.5\end{array}$

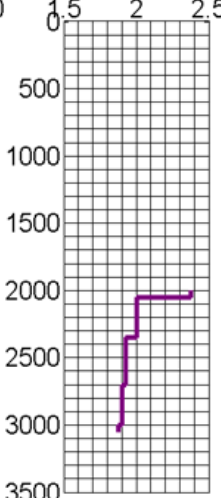

Figure 1 - (Left column) Residual function maps demonstrating the complexity of Equation 1 (Blias, 2009) for a PP wave reflection event of the (A) Model 1, (B) Model 2 and (C) Model 3. Red dispersions represent the global minimum region and the blue dispersions represent the local minimum region. (Right column) The velocity profile of the P-wave velocity (Vp), S-wave velocity (VS) and velocity ratio between the P-wave and S-wave velocities (VpNS) of the (D) Model 1, (E) Model 2 and (F) Model 3. 
A

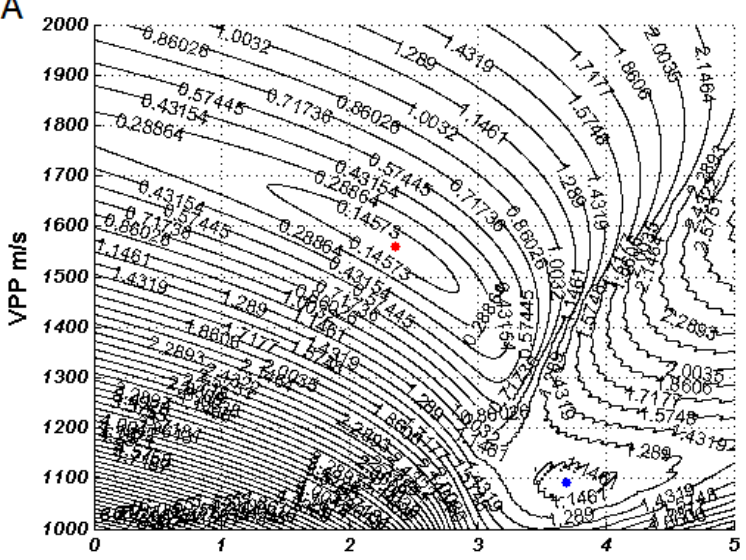

B

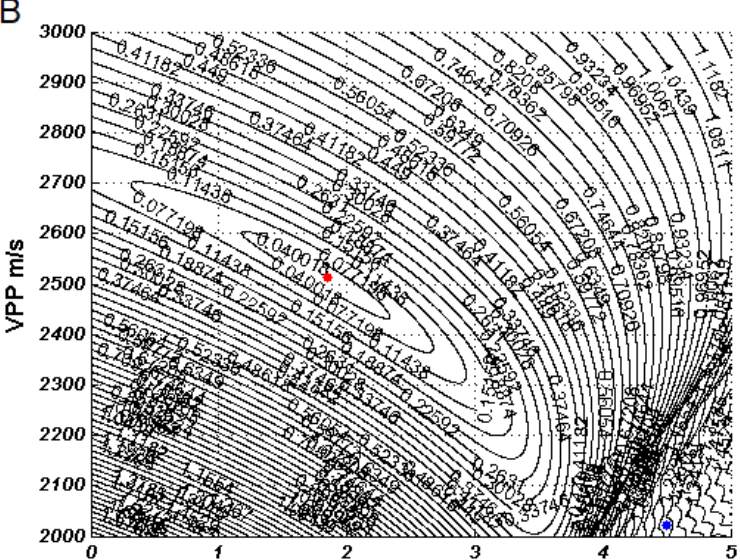

C

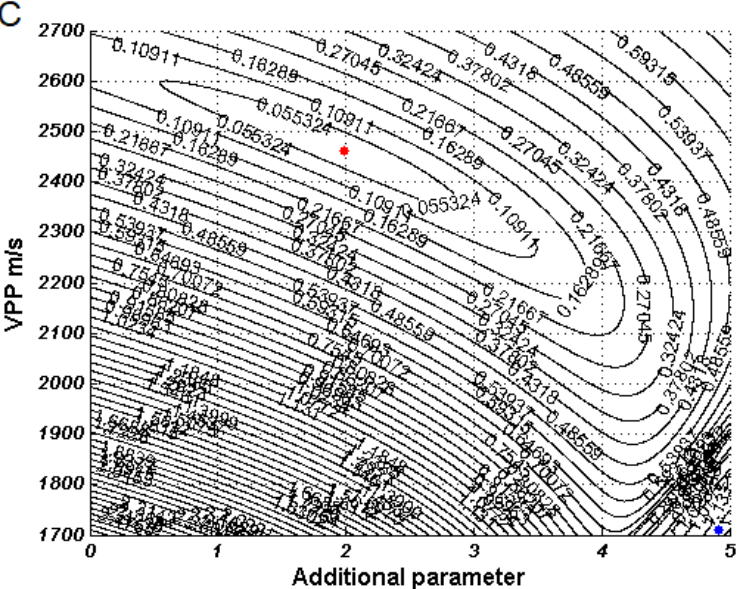

D
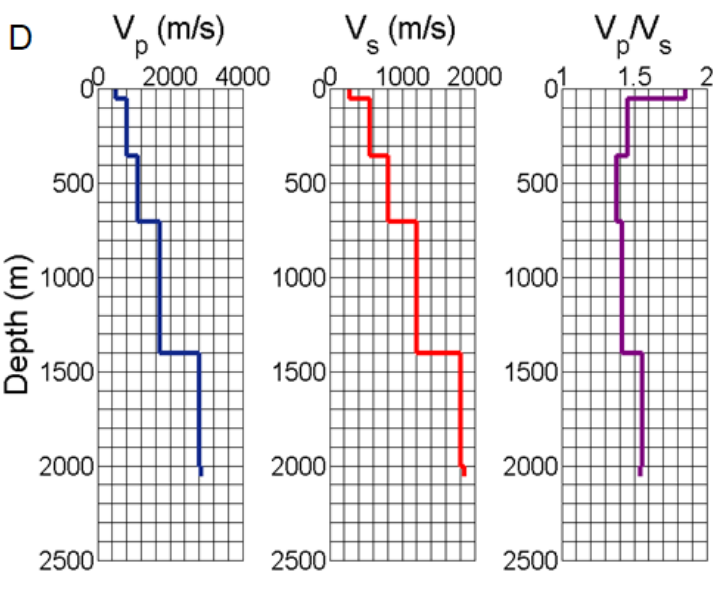

E
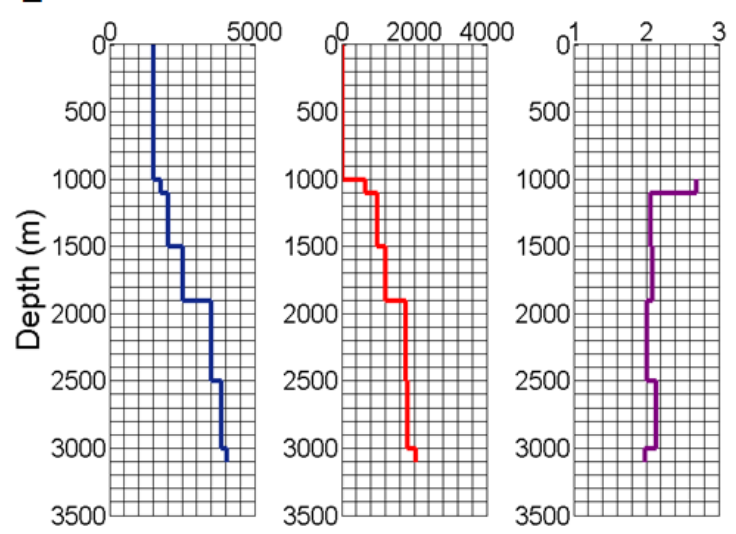

$\mathrm{F}$

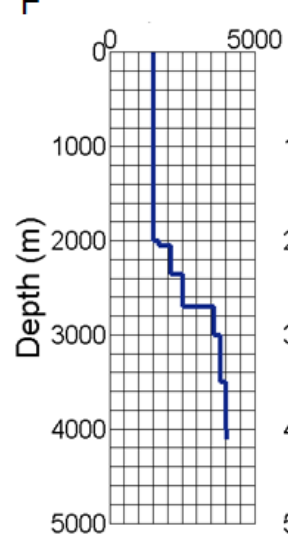

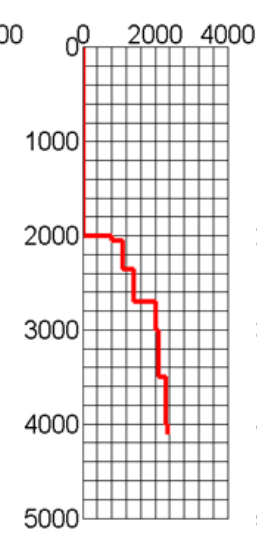

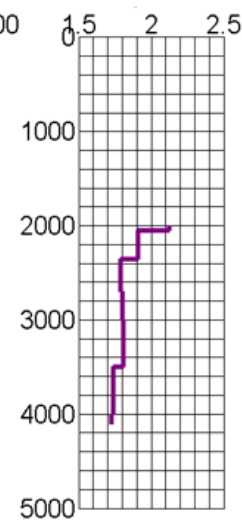

Figure 2 - (Left column) Residual function maps demonstrating the complexity of Equation 1 (Blias, 2009) for a PP wave reflection event of the (A) Model 4, (B) Model 5 and $(\mathrm{C})$ Model 6 . Red dispersions represent the global minimum region and the blue dispersions represent the local minimum region. (Right column) The velocity profile of the P-wave velocity (Vp), S-wave velocity (Vs) and velocity ratio between the P-wave and S-wave velocities (Vp/Vs) of the (D) Model 4, (E) Model 5 and (F) Model 6. 
A

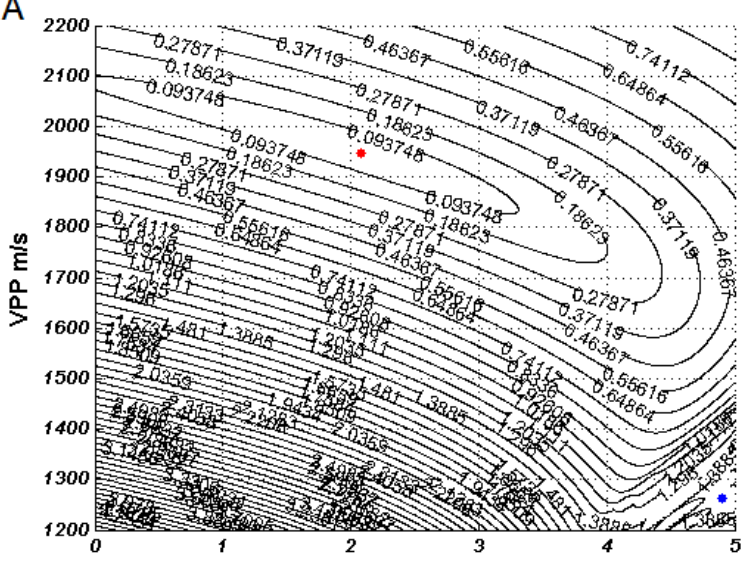

$\mathrm{B}$

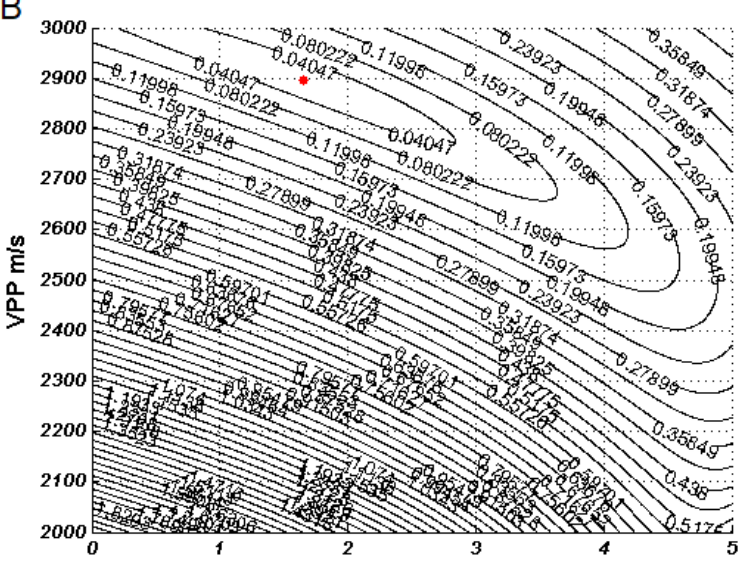

C

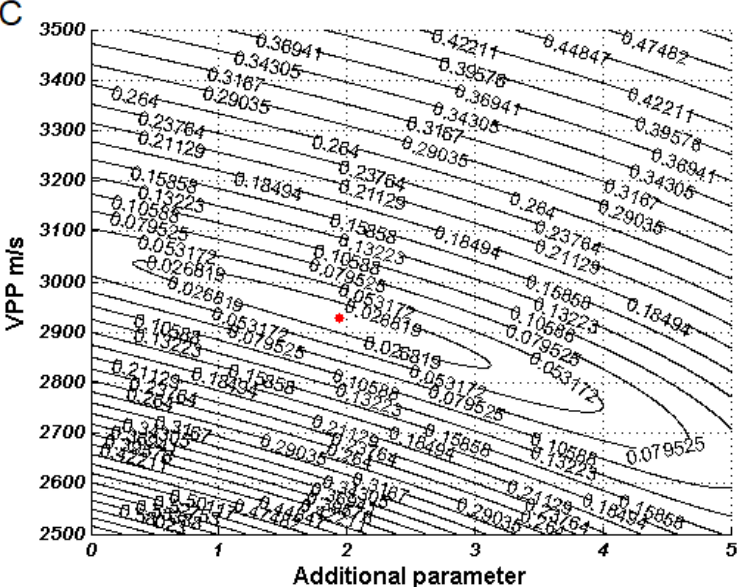

D
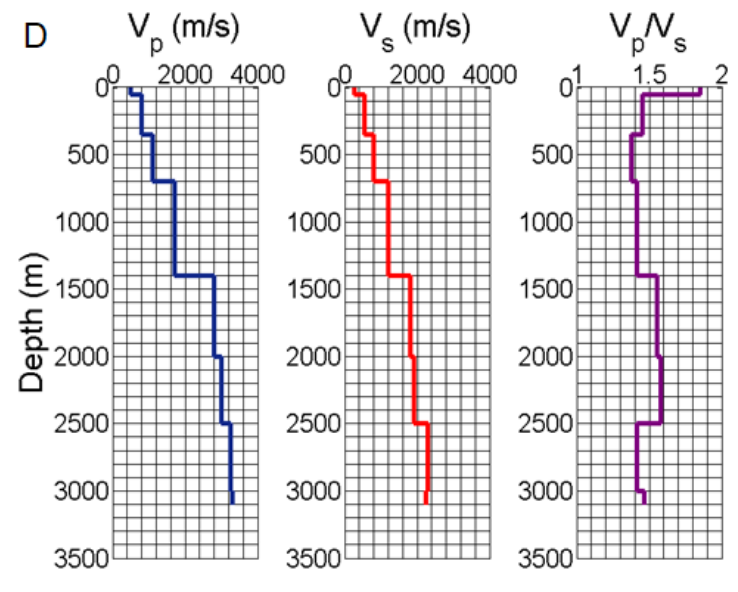

E
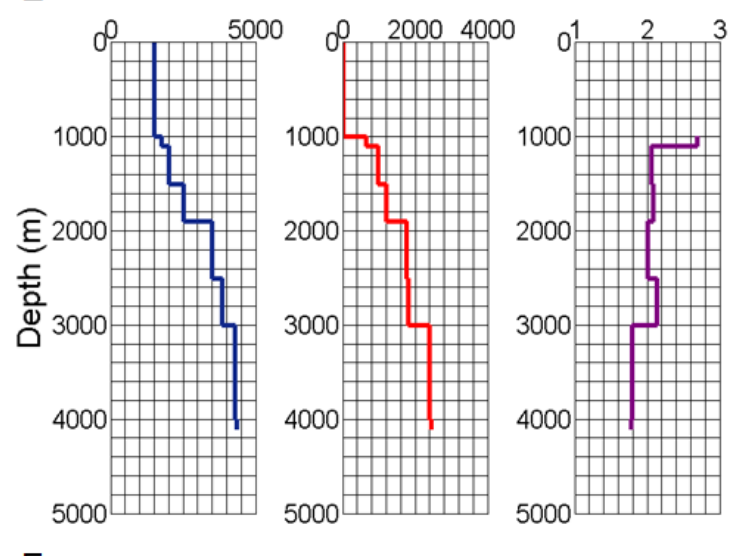

$\mathrm{F}$

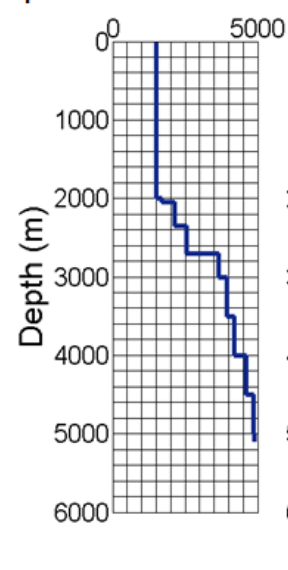

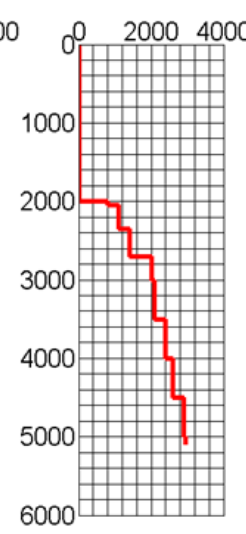

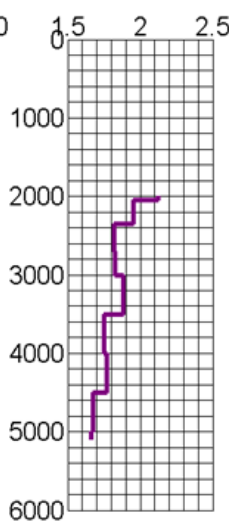

Figure 3 - (Left column) Residual function maps demonstrating the complexity of Equation 1 (Blias, 2009) for a PP wave reflection event of the (A) Model 7, (B) Model 8 and (C) Model 9. Red dispersions represent the global minimum region and the blue dispersions represent the local minimum region. (Right column) The velocity profile of the P-wave velocity (Vp), S-wave velocity (Vs) and velocity ratio between the P-wave and S-wave velocities (Vp/Ns) of the (D) Model 7, (E) Model 8 and (F) Model 9. 
A

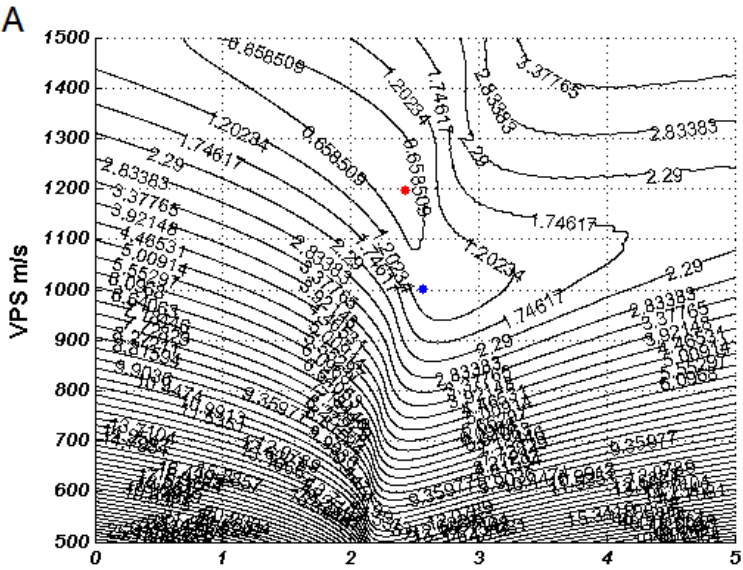

B

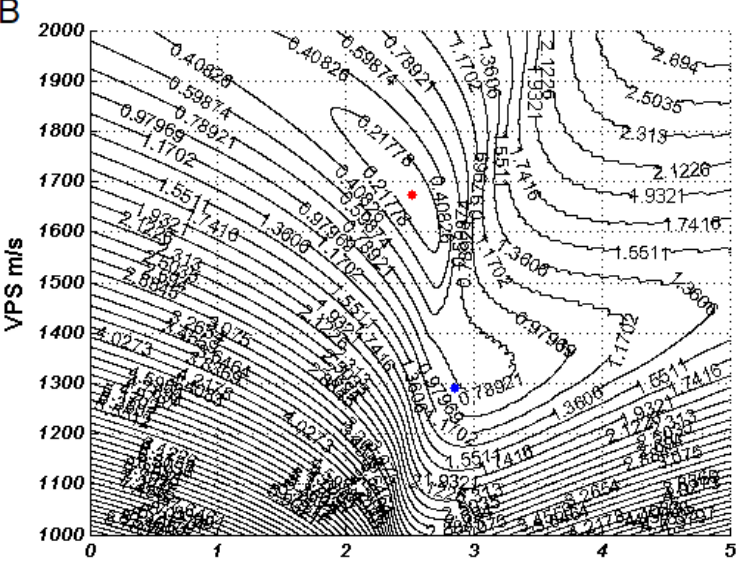

C

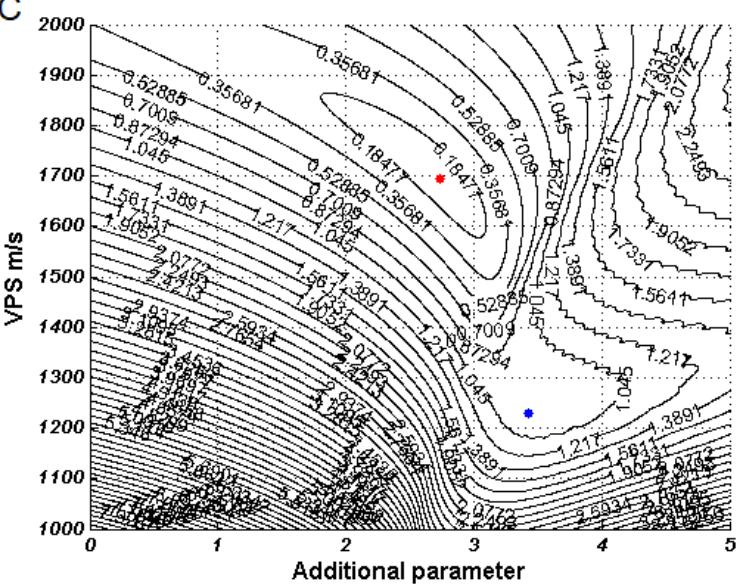

D

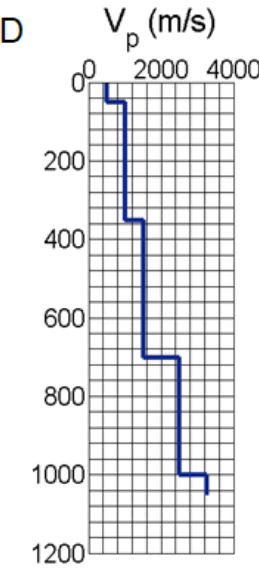

E
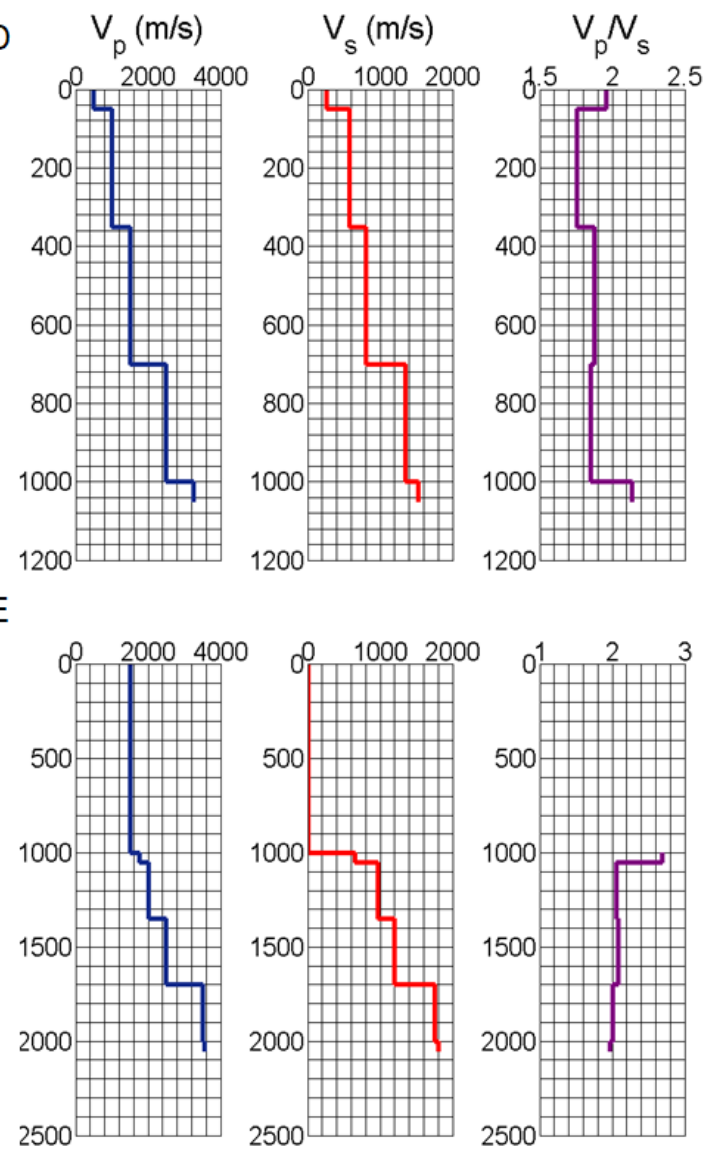

$\mathrm{F}$

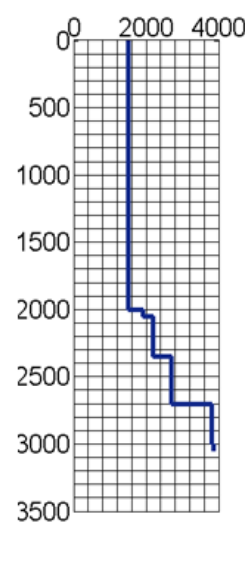

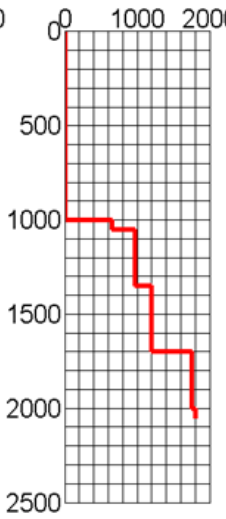

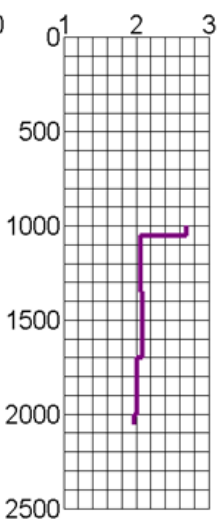

O 20004000
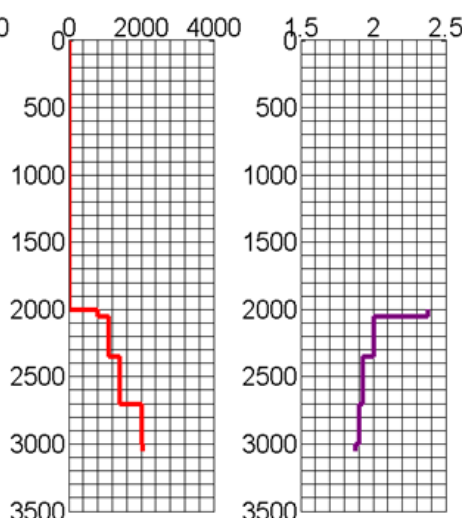

Figure 4 - (Left column) Residual function maps demonstrating the complexity of Equation 1 (Blias, 2009) for a PS wave reflection event of the (A) Model 1, (B) Model 2 and $(\mathrm{C})$ Model 3. Red dispersions represent the global minimum region and the blue dispersions represent the local minimum region. (Right column) The velocity profile of the P-wave velocity (Vp), S-wave velocity (Vs) and velocity ratio between the P-wave and S-wave velocities (Vp/Vs) of the (D) Model 1, (E) Model 2 and (F) Model 3. 
A

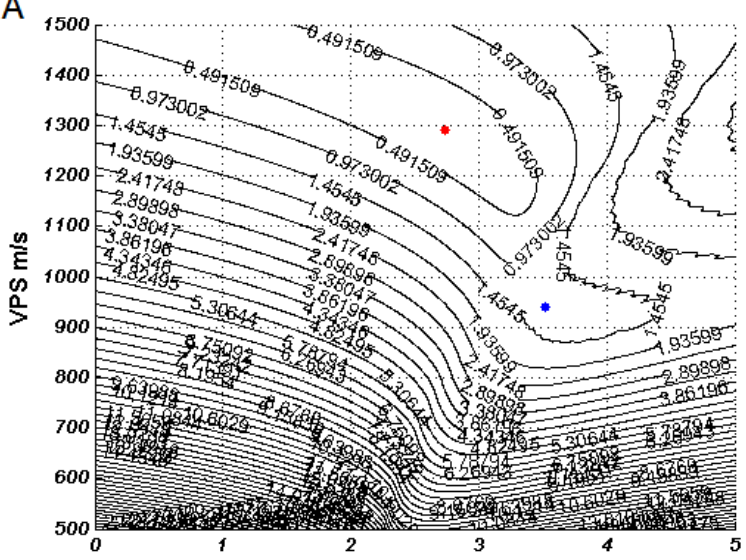

B

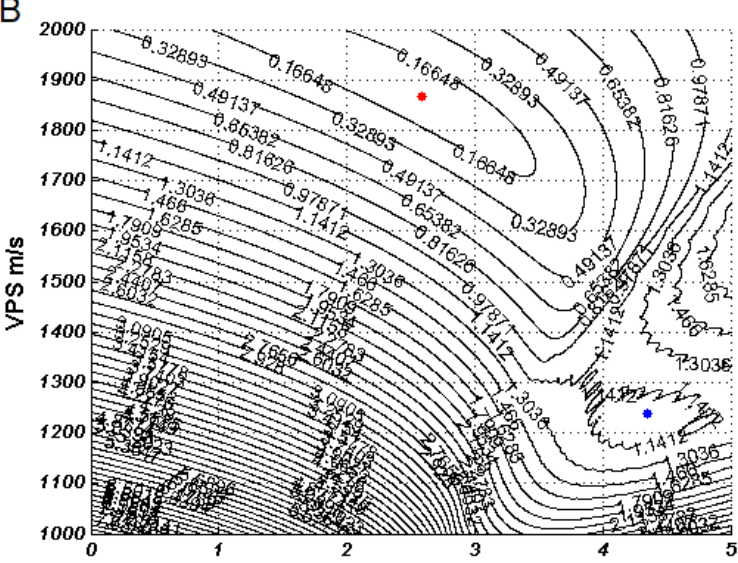

C

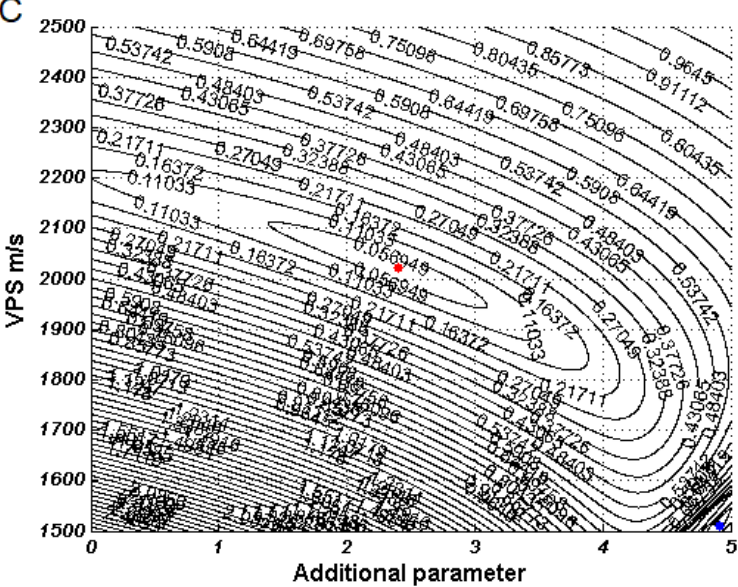

$\mathrm{D}$
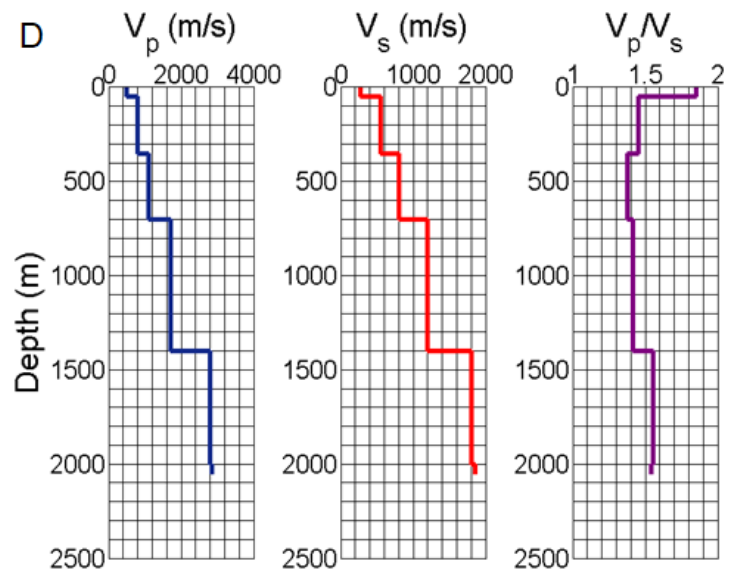

$\mathrm{E}$
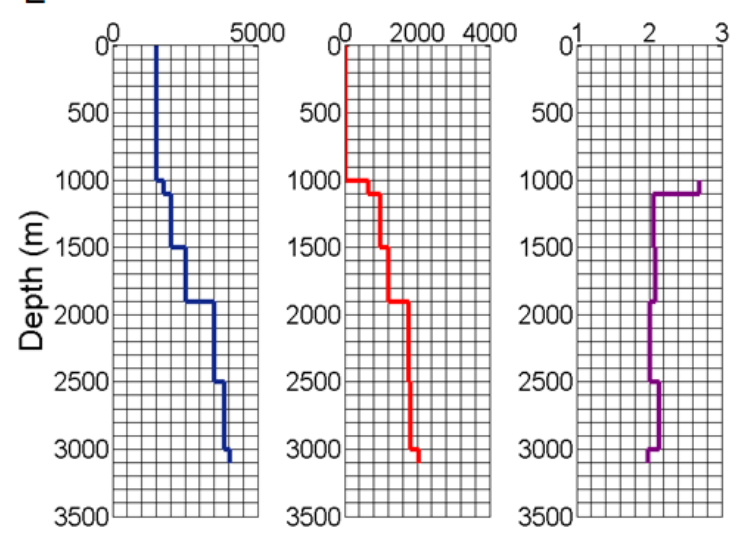

$\mathrm{F}$

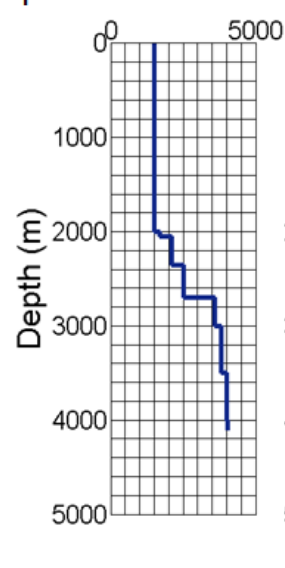

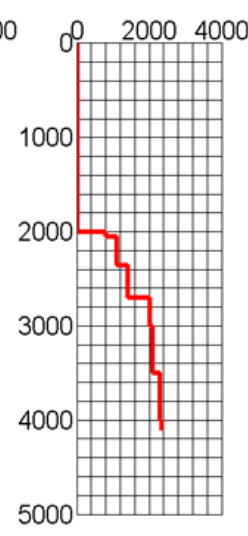

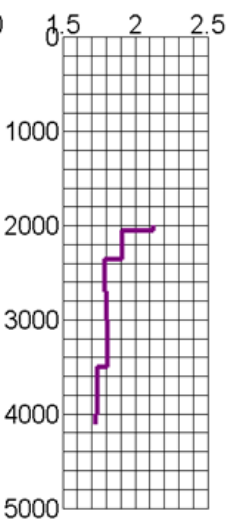

Figure 5 - (Left column) Residual function maps demonstrating the complexity of Equation 1 (Blias, 2009) for a PS wave reflection event of the (A) Model 4, (B) Model 5 and $(\mathrm{C})$ Model 6 . Red dispersions represent the global minimum region and the blue dispersions represent the local minimum region. (Right column) The velocity profile of the P-wave velocity (Vp), S-wave velocity (Vs) and velocity ratio between the P-wave and S-wave velocities (Vp/Vs) of the (D) Model 4, (E) Model 5 and (F) Model 6. 
A

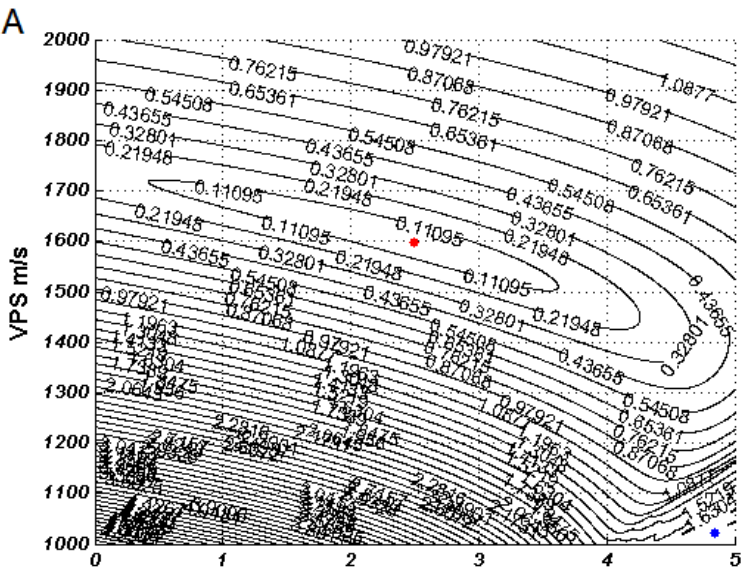

B

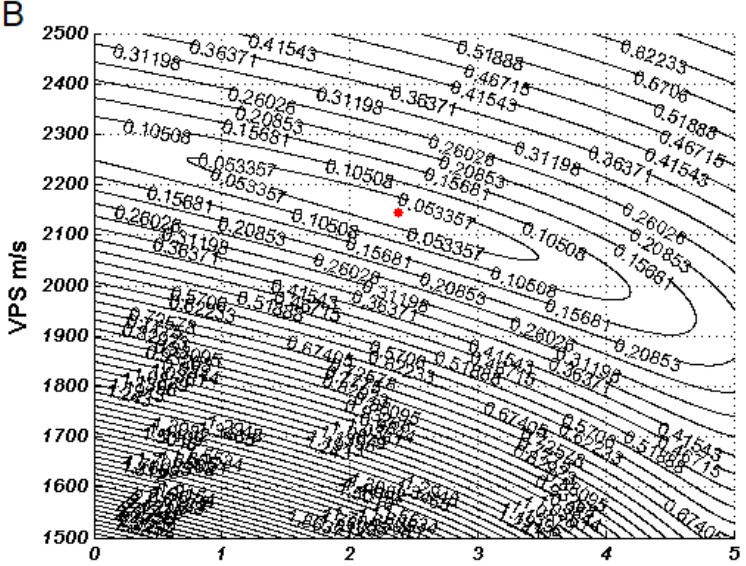

C

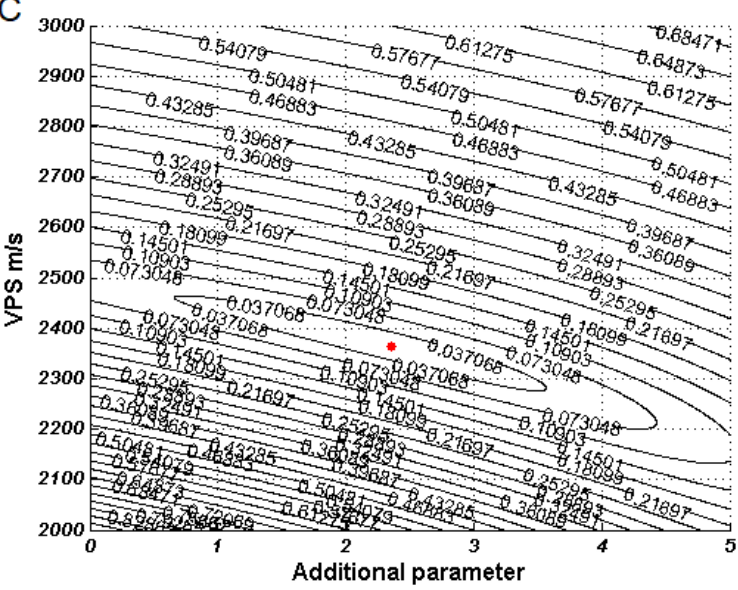

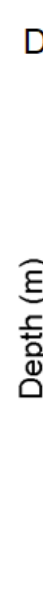

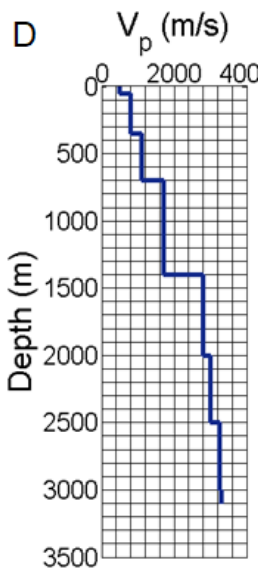

E

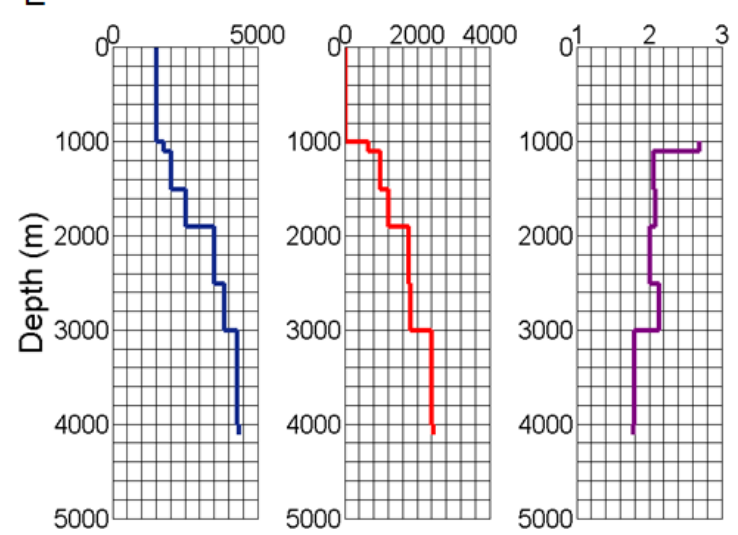

$\mathrm{F}$

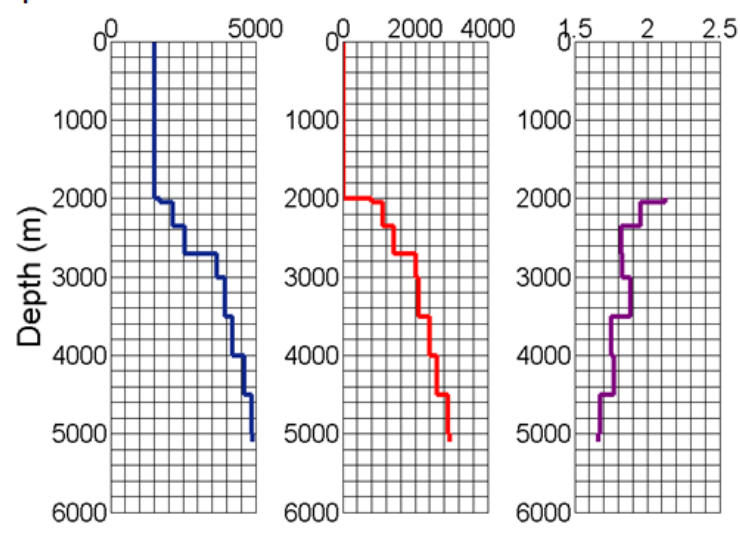

Figure 6 - (Left column) Residual function maps demonstrating the complexity of Equation 1 (Blias, 2009) for a PS wave reflection event of the (A) Model 7, (B) Model 8 and $(C)$ Model 9 . Red dispersions represent the global minimum region and the blue dispersions represent the local minimum region. (Right column) The velocity profile of the P-wave velocity (Vp), S-wave velocity (VS) and velocity ratio between the P-wave and S-wave velocities (Vp/NS) of the (D) Model 7, (E) Model 8 and (F) Model 9. 
while for the PP wave reflection event, it happens only in the Model 6.

The attenuation of the complexity of the topography seems to happen more with an increase of the structure thickness than with the increase of the water depth.

\section{CONCLUSIONS}

There is a significant decrease in the complexity of the objective function as the top of the reservoir becomes deeper. However, for both reflection events, the increase of the water depth interferes significantly less than the increase of the thickness of the rock structure above the top of the reservoir.

The displacement of the global minimum region and of all structure is much more subtle in the abscissa axis than that in the ordinate axis, what shoed that the additional parameter, the heterogeneity parameter, is much less sensible than the RMS velocity.

Thus, it is evident, based on the data observed, that the mitigation of the complexity concerning the topographic structure of the objective function is associated to the increase of the RMS velocity, and it becomes clearer when the local minimum region of the converted wave event, the one with lower RMS velocity, attenuates after than the local minimum region of the conventional reflection event.

\section{ACKNOWLEDGEMENTS}

This work was kindly supported by the Brazilian research agency CAPES (Coordenação de Aperfeiçoamento de Pessoal de Nível Superior)

\section{REFERENCES}

ALEIXO R \& SCHLEICHER J. 2010. Traveltime approximations for q-P waves in vertical transversely isotropy media. Geophysical Prospecting, 58(2): 191-201.

ALKHALIFAH T \& TSVANKIN I. 1995. Velocity analysis for transversely isotropic media. Geophysics, 60(5): 1550-1566.

BLIAS E. 2009. Long-offset NMO approximations for a layered VTI model: Model study. In: 79th Anual International Meeting. p. 3745-3749. Houston: Society of Exploration Geophysicists, Expanded Abstract, Houston.
DIX CH. 1955. Seismic velocities from surface measurements. Geophysics, 20(1): 68-86.

GOLIKOV P \& STOVAS A. 2012. Accuracy comparison of nonhyperbolic moveout approximations for qP-waves in VTI media. Journal of Geophysics and Engineering, 9(4): 428-432.

KURT H. 2007. Joint inversion of AVA data for elastic parameters by bootstrapping. Computers \& Geosciences, 33(3): 367-382.

LARSEN JA. 1999. AVO inversion by simultaneous P-P and P-S inversion. Master's dissertation. University of Calgary, Department of Geology and Geophysics. Calgary. 124 pp.

LI XY \& YUAN J. 2001. Converted-wave Imaging in Inhomogeneous, Anisotropic Media-Part I-Parameter Estimation. In: 63rd EAGE Conference \& Exhibition. Expanded Abstract, Amsterdam, The Netherlands. v. 1, p. 109.

MALOVICHKO AA. 1978. A new representation of the traveltime curve of reflected waves in horizontally layered media. Applied Geophysics (in Russian), 91(1): 47-53.

MUIR F \& DELLINGER J. 1985. A practical anisotropic system. SEP-44, 55: 58 .

URSIN B \& STOVAS A. 2006. Traveltime approximations for a layered transversely isotropic medium. Geophysics, 71(2): D23-D33.

ZUNIGA NRCF. 2017. Análise comparativa de aproximações não-hiperbólicas dos tempos de trânsito de dados sísmicos multicomponente utilizando tecnologia OBN. Master's dissertation. Universidade de São Paulo. Brazil. 86 pp.

ZUNIGA NRCF, BOKHONOK 0 \& DIOGO LA. 2015. Comparison of nonhyperbolic travel-time approximations for multicomponent seismic data. In: 14th SBGf Congress. Expanded Abstract, Rio de Janeiro, Brazil. p. 1176-1181

ZUNIGA NRCF, MOLINA EC \& PRADO RL. 2016a. Inversion of multicomponent seismic data for VTI medium using the globalized Nelder-Mead optimization algorithm. In: 3rd EAGE/SBGf Workshop 2016. Rio de Janeiro, Brazil.

ZUNIGA NRCF, MOLINA EC \& PRADO RL. 2016b. Inversion of Multicomponent Seismic Data of the Santos Basin. In: Far East Hydrocarbons. Expanded Abstract, EAGE, Russia.

ZUNIGA NRCF, MOLINA EC \& PRADO RL. 2017. Comparison of travel-time approximations for unconventional reservoirs from Santos Basin, Brazil. Brazilian Journal of Geophysics, 35(4): 273-286. 